\title{
Article \\ Quality Control in Fiore Sardo PDO Cheese: Detection of Heat Treatment Application and Production Chain by MRI Relaxometry and Image Analysis
}

\author{
Roberto Anedda *(D), Riccardo Melis (D) and Elena Curti (D) \\ Porto Conte Ricerche s.r.l., S.P. 55 Porto Conte-Capo Caccia, Km 8.400 Loc. Tramariglio, 07041 Alghero, SS, Italy; \\ melis@portocontericerche.it (R.M.); curti@portocontericerche.it (E.C.) \\ * Correspondence: anedda@portocontericerche.it; Tel.: +39-079-998-578
}

check for

updates

Citation: Anedda, R.; Melis, R.; Curti, E. Quality Control in Fiore Sardo PDO Cheese: Detection of Heat Treatment Application and Production Chain by MRI Relaxometry and Image Analysis. Dairy 2021, 2, 270-287. https:// doi.org/10.3390/dairy2020023

Academic Editors: Pierluigi Caboni and Paola Scano

Received: 4 March 2021

Accepted: 13 May 2021

Published: 26 May 2021

Publisher's Note: MDPI stays neutral with regard to jurisdictional claims in published maps and institutional affiliations.

Copyright: (C) 2021 by the authors Licensee MDPI, Basel, Switzerland. This article is an open access article distributed under the terms and conditions of the Creative Commons Attribution (CC BY) license (https:/ / creativecommons.org/licenses/by/ $4.0 /)$.

\begin{abstract}
Fiore Sardo (FS), a traditional Italian cheese, is present in the market as a heterogeneous variety of products. The use of heat-treated (HT) milk is forbidden by the official production protocol, but no official analytical method able to detect heat application is yet available. Here, a combined magnetic resonance imaging (MRI) relaxometry and image analysis approach to recognize FS made from raw milk is presented. Artisanal FS cheeses were produced from raw milk (RC) by five shepherds in accordance with the official protocol. They were compared to HT-milk counterparts (HTC). Additionally, industrially manufactured commercial FS cheeses (I) were also purchased and compared to RC and HTC. Relaxometry data of FS indicated the presence of two water populations; the ratio of characteristic relaxation time constant $\mathrm{T}_{2}$ and area fraction (Score, $\dot{\mathrm{S}}$ ) of the fastest relaxing population was used to compare RC, HTC and I samples. RC from HTC were successfully discriminated, the latter exhibiting lower Ș (enhanced protein hydration). I cheeses exhibited the lowest $\dot{S}$ values, sometimes comparable to HTC. Since visual appearance of RC and HTC is appreciably different, an image analysis deep learning approach using MRI and photographic pictures was adopted to discriminate the two productions, with promising percentages $(>93 \%)$.
\end{abstract}

Keywords: magnetic resonance imaging (MRI); image analysis; Fiore Sardo; cheese; microstructure; dairy chemistry; thermised milk; raw milk; protected designation of origin

\section{Introduction}

Protected Designation of Origin (PDO) describes a group of agricultural/food products originating from a specific geographical area, for which production, processing and preparation must take place according to a recognised know-how [1].

In the European Union, 185 cheeses are registered as PDO products; this number rises to 231 if cheeses registered as Protected Geographical Indications (PGI) are considered [2]. A first classification of these products can be made based on milk processing. A total of 91 cheeses out of 231 (PDO + PGI) compulsorily require the use of raw milk; in other cases, the use of both raw and pasteurized/heat-treated milk is allowed. The lack of a specific requirement allows producers to freely decide how to process milk, leading to cheeses characterized by very different attributes [3].

The effects of milk heat treatment on cheese features have been extensively investigated and explained. From a microbiological and sensory point of view, the heat treatment depletes pathogens along with the characteristic microbiota, resulting in a more uniform final product that exhibits a less characteristic flavour profile compared to the raw milk counterpart [4]. From a technological point of view, though the application of a heat treatment guarantees improved hygienic conditions during processing and a better safety of the final product, it can result in an impaired coagulation and syneresis and in an alteration of cheese rheology and texture [5,6]. 
Fiore Sardo PDO (FS) cheese is the oldest cheese of Sardinia (Italy), being historically produced by shepherds in very small artisanal cheese factories. It must be obtained exclusively using raw whole milk from the Sarda Sheep breed. The official cheesemaking protocol still follows the ancient traditional process [7]. The peculiarities of the manufacturing process confer to Fiore Sardo a firm, crumbly and grainy texture, which easily breaks into flakes, and a savoury, piquant and smoky flavour [8-11]. Market offer is characterized by a quite heterogeneous variety of Fiore Sardo PDO, with very different quality attributes, with almost $90 \%$ of the product supplied by the dairy industry (Agris Sardegna, 2015).

In particular, the use of heat-treated milk for FS production has been associated with common industrial processing practices [12-15]. Previous studies concluded that this practice cannot be excluded [16] and that it is not unrealistic that some FS are manufactured using heat-treated milk, against the specifications indicated in the EC Regulation. From a scientific point of view, several chemical and physical characteristics of some productions were found to be reasonably explained by assuming the effects of thermal treatments on milk [16]. This is also supported by the fact that no official analytical methods able to discriminate between ewe milk cheese obtained from raw and thermised milk are available [17].

Some analytical techniques able to discriminate products made from raw milk and heat-treated milk have been proposed for product quality safeguards [17-21].

Analytical approaches based on nuclear magnetic resonance (NMR) relaxometry are particularly interesting. This technique was previously applied to describe the thermal denaturation of whey proteins and other milk components. Lambelet et al. [22], for example, demonstrated that irreversible thermal denaturation of whey proteins can be detected by low-field NMR. They observed that when NMR transverse relaxation rates were plotted versus heating temperature, a sigmoid curve was obtained, with relaxation rate values showing a steep increase from about $60^{\circ} \mathrm{C}$ to about $80^{\circ} \mathrm{C}$, and a flex corresponding to milk thermisation/pasteurization temperatures usually adopted in dairy industrial processing $\left(64{ }^{\circ} \mathrm{C}\right.$ to $72{ }^{\circ} \mathrm{C}$ range). Later work by the same research group extended the results to other milk components and dyalized skim milk [23], suggesting the suitability of NMR relaxometry for measuring the thermal denaturation of milk proteins. Recent works, based on a high sample numerosity and exploiting an experimental setup more closely resembling real industrial processing conditions, demonstrated that the effect of heat treatment on milk is transferred to NMR relaxometry characteristics of both rennet curd and aged cheese. Raw and heat-treated milk [24] and derived curds $[25,26]$ could be successfully discriminated by benchtop low-field NMR relaxometry. A similar discriminative ability of NMR relaxometry was also observed in ewe milk mature cheese by high-field magnetic resonance imaging (MRI) [19].

The aforementioned investigations demonstrated the sensitivity of NMR relaxation parameters to key cheesemaking processes (mainly thermal treatments of milk) in real dairy systems (whole milk, curds, mature cheese), suggesting the suitability of NMR relaxometry as a valid and useful tool in quality control activities in the dairy industry and for the safeguard of typical dairy productions.

In this study, heat treatments of milk were intentionally applied to produce FS cheese, and NMR relaxometry of raw and heat-treated FS were compared. Moreover, a comparison between artisanal and some industrial FS, the latter purchased from the market and visibly different from the typical FS PDO, was carried out for a more comprehensive evaluation of the effect of production chain on relaxometry features and aiming to optimize the exploitation of NMR relaxometry to assess the adherence to the official production protocol. MRI was used to compare heat-treated samples to their raw counterparts. A supplemental investigation was also carried out by exploiting image analysis protocols on a selected subset of MRI images and digital pictures in order to correlate process-induced changes with MRI image features and the visual appearance of samples. 


\section{Materials and Methods}

Two sets of experiments were carried out, as summarized in Table S1. The first dataset (Dataset 1) was acquired by analysing samples made by different artisanal producers in different seasons. Additionally, a selection of industrial cheeses was purchased from the local market and subjected to the same analytical protocol used to characterize samples from Dataset 1.

\subsection{Production of Fiore Sardo (FS) Cheese}

\subsubsection{Dataset 1}

Five shepherds (S1, S2, S3, S4, S5) who were artisanal manufacturers of Fiore Sardo were selected for cheese sample production. Each shepherd produced a total of 20 cheese wheels in two different seasons (March-April 2019, Season 1; January-February 2020, Season 2; 100 cheese wheels in total for the two seasons). Ten wheels out of 20 were produced from raw milk, while the remaining ten were produced from the same milk after thermisation. Milk thermisation was carried out in different industrial plants, using plate heat exchanger modules. Cheesemaking was performed according to the official cheesemaking protocol $[7,9]$, but milk thermisation was used for selected samples. Aged cheese samples were collected after 105 and 180 days of ripening in each shepherd's cellar. One quarter portion of each cheese wheel was sampled at each of the abovementioned time points, for a total of 10 wheels per producer per ripening time, 5 of which were made from raw milk (RC) and 5 from heat-treated milk (HTC).

\subsubsection{Dataset 2}

Industrial FS cheeses with similar ripening (6-8 months) were purchased from the local market in different seasons (January-November). Both cheeses manufactured by industrial dairy factories (11 samples) and from a maturer industry (2 samples) were purchased. Maturer industries buy Fiore Sardo from artisan producers and ripen these cheeses in their industrial cellars for several months, until they can be released to the market, i.e., after at least 105 days of ripening, according to the official cheesemaking protocol. Fiore Sardo PDO cheeses from the maturer industry are sold with the industrial brands, but milk is processed by shepherds and small artisans according to traditional processes [9]. A schematic representation of sample production and experimental plans (relative to both Dataset 1 and Dataset 2) is reported in Figure S1 (Supplementary Material).

\subsection{Magnetic Resonance Imaging (MRI) Analysis}

Each analytical sample of cheese subjected to MRI analysis represented the most central part of the cheese wheel, as schematically depicted in Figure S2.

In brief, each quarter was carefully cut in the portion corresponding to the wheel centre to obtain one cylindrical sample (diameter $2.3 \mathrm{~cm}$, height $3-4 \mathrm{~cm}$ ) to easily fit into a $50 \mathrm{~mL}$ Falcon tube. All samples were equilibrated to $22^{\circ} \mathrm{C}$ for $1 \mathrm{~h}$ before MRI analysis. MRI experiments were performed using a Bruker Avance $300 \mathrm{MHz}$ equipped with a microimaging Micro2.5 probe (Bruker Biospin, Karlsruhe, Germany) at room temperature (approximately $22-24^{\circ} \mathrm{C}$ ). A conventional Carr Purcell Meiboom Gill (CPMG) spin echo sequence was used with the following parameters: single $1 \mathrm{~mm}$ slice; echo time $(\mathrm{TE})=$ $7.907 \mathrm{~ms}$; repetition time $(\mathrm{TR})=3 \mathrm{~s}$; echoes $=64$; matrix $=128 \times 128$; number of excitations $=1-3$; acquisition time $=25 \mathrm{~min}$. To selectively analyse signals from water, the fat signal was suppressed, taking advantage of the different chemical shifts of fat and water at 7.05 $\mathrm{T}$, with a $90^{\circ}$ selective pulse applied before the conventional CPMG spin echo sequence at a frequency offset of $3.5 \mathrm{ppm}$ with respect to water (preparatory fat saturation scheme provided by Bruker Topspin). All MR images were characterized by a signal to noise ratio higher than 100. 
The AnalyzeNNLS software package was used to deconvolute the multi-exponential transversal relaxation time $\left(\mathrm{T}_{2}\right)$ decay of water proton signals [27]. Bruker MRI image data were converted into multiecho image data (MEID) files (Matlab, R2020b, The Mathworks, Sherborn, MA). Regions of interest (ROIs) were manually drawn on the MEID file (five ROIs for each image) and automatically processed to obtain the geometric mean $\mathrm{T}_{2}\left(\mathrm{~T}_{2}\right.$ relaxation time constant, corresponding to the maximum intensity of the peak, on a logarithmic scale) and the area fraction (obtained by dividing the sum of the $\mathrm{T}_{2}$ distribution within a desired region between $T_{2}$ min and $T_{2}$ max by the sum of all $T_{2}$ distributions).

\subsection{Moisture Content}

Moisture content was measured using the rapid determination method for cheese $\left(130{ }^{\circ} \mathrm{C}, 90 \mathrm{~min} ;[28]\right)$.

\subsection{Statistical Analysis}

The effect of thermisation was evaluated by comparing MRI parameters (geometric mean $\mathrm{T}_{2}$ and area fractions) between RC and HTC by using univariate Student's $t$-test. An additional statistical comparison (one-way ANOVA, followed by Tukey post-hoc test) was performed to compare each shepherd's (i.e., artisanal) production to the industrial and maturer industry cheeses. Industrial cheeses (11 samples) were considered as a unique group of data, as were maturer cheeses ( 2 samples). Both tests were carried out with the MetaboAnalyst tool (https: / / www.metaboanalyst.ca, v.5, accessed 20 November 2020) [29], considering a significance threshold limit of $p<0$. 05. Box plots were obtained using MetaboAnalyst.

\subsection{MRI Data Conversion}

$\mathrm{T}_{2}$ MRI Bruker Paravision raw 2dseq data from full Dataset 1 were first converted to Neuroimaging Informatics Technology Initiative (NIfTI, .nii) format using Bru2nii software (Bruker2NIfTI v1.0.20180303: by Matthew Brett, Andrew Janke, Mikaël Naveau, Chris Rorden, Windows 64-bit) with a resizing factor of 10 . Then, the 64 slices from each NIfTI file were converted in JPEG format using a Matlab script first developed by Alex Laurence [30]. Only MRI images derived from the first MSME slice (TE = $7.907 \mathrm{~ms}$ ) were used for deep transfer learning classification purposes.

\subsection{Photographic Acquisition and Processing of Cheese Paste Surfaces}

Snapshots of the surface of Fiore Sardo cheese from Dataset 1 produced in Season 1 at 105 days of ripening were taken using a Machine Vision System (MVS) assembled in our laboratory. Briefly, our MVS consisted of a portable plastified (PVC) white light-box (24 $\times 23 \times 22 \mathrm{~cm}$ ) equipped with a USB LED strip of white-light-emitting diode lamp (input $5 \mathrm{~V}$, lumen 550, colour temperature $6500 \mathrm{~K}$ ), assembled on a metallic support and directed upwards at a $90^{\circ}$ angle with a cardboard box wall (Figure S3). Photos were taken without flash using a 25-megapixel-wide camera integrated in a Galaxy A50 smartphone. Cheese quarters were placed under a dark background and manually adjusted to be below the camera with a fixed distance of $25 \mathrm{~cm}$. All operations were carried out in a dark room to minimize the effect of outside light. The acquired images (Joint Photographic Expert Group-JPEG; 24-bit colour depth, spatial resolution $3072 \times 2048$ pixels) were stored on a removable memory card. Images were finally processed by removing black background and manually cropped by using in-house-modified scripts available in the Matlab Image Processing Toolbox (Matlab, R2020b, The Mathworks, Sherborn, MA, USA).

Both digital pictures and MRI images were reordered in a concatenated folder structure according to the scheme illustrated in Figure S4. Each subfolder, related to the two ripening stages for each season, was separately compressed in zip format as input data for the deep learning classification described in the following section. 


\subsection{Deep Transfer Learning Based Classification}

The proposed classification method relies on the deep transfer learning approach based on deep neural network (DNN) architectures. DNNs consist of a series of functions that take an input and return a predicted label. For this purpose, labeled input data were initially split into a training dataset (i.e., the set of data used to fit the model) and a validation dataset (i.e., the set of data used to provide an unbiased evaluation of a model fit on the training dataset while optimizing, or tuning, the model parameters). In brief, labeled input data pass through the DNN network using a loss function to evaluate how well the model performs at correctly identifying the true classes. The model optimizes for this loss function by computing the gradient of the loss function with respect to the model parameters. In parallel, the validation process optimizes the model parameters iteratively to minimize the loss and perform validation of the trained model [31]. Six pre-trained DNN frameworks were tested: ResNet [32], AlexNet [33], VggNet [34], SqueezeNet [35], DenseNet [36] and Inception-Net [37]. All models were implemented using the learning framework Pytorch, written in Python v. 3.7 and integrated into the open source GPU web server Google Colaboratory [38]. For the training step, all six DNN frameworks were trained under the following conditions: number of epoch $=1000$; batch size $=8$; learning rate $=0.001$; momentum $=0.9$. When the loss function converged and stabilized, the training step was automatically stopped and the training model saved. For the validation set, $20 \%$ of the training dataset data was used, and a 5 -fold cross validation was performed to evaluate the performance of each model. Each model was trained 5 times on each dataset, and related performance parameters (training and validation accuracy and loss as well as training time) were computed. Finally, for all pre-trained models, the average values of the five replicates were calculated and listed in tables in order to compare classification performance.

\section{Results and Discussion}

\subsection{MRI Analysis of Dataset 1}

NMR relaxation of protons can occur only if stimulated by a fluctuating field of proper frequency that would induce the spin transition, in a non-spontaneous relaxation process that finally leads to equilibrium magnetization. Longitudinal relaxation, defined by the constant $\mathrm{T}_{1}$, is triggered by field fluctuations at the Larmor frequency. Contrarily, in solid or semi-solid systems such as cheese, the major contribution of transverse relaxation, described by $\mathrm{T}_{2}$, comes from the slow molecular dynamics of the studied liquid at zero Larmor frequency. For this reason, observed $T_{1}$ values usually present a very broad distribution, while populations are sharper and generally better defined for $T_{2}$. We chose the latter NMR relaxometry constant to describe the analysed cheeses.

Informative relaxometry features of the samples can be derived by analysing the multiexponential decay of the transverse magnetization from CPMG experiments at variable interpulse spacing $[19,27,39]$. Fitting of CPMG decays of MRI images of FS cheeses indicated a multiexponential behaviour (i.e., two $\mathrm{T}_{2}$ populations), deriving from the presence of two water proton pools (Figure 1).

Multiexponential decay of the transverse component of NMR magnetization arises from the combined effect of diffusive and chemical exchange phenomena. In this condition, water molecules in cheese could be described, at a first approximation, as either free water or hydration water molecules (i.e., water embedded in the protein matrix and strongly interacting with it). Of course, the term "free" could be misleading, since water dynamics in this fraction are in fact much slower than in bulk water. NMR relaxometry is able to clearly detect the presence of different water pools, since water molecules sample different domains within the time scale of the CPMG experiment (i.e., the interpulse spacing). When diffusion is slow (and/or when relaxation domains are large), water molecules in the free water domain and hydration water retain their characteristic relaxation times, and multiexponential distribution is observed (e.g., in aged cheese); when diffusion is fast (and/or heterogeneity of domains is small) (e.g., in protein solutions, milk and curd), 
relaxation of water in different compartments is averaged, and proton transverse relaxation is mainly monoexponential $[24,39,40]$.

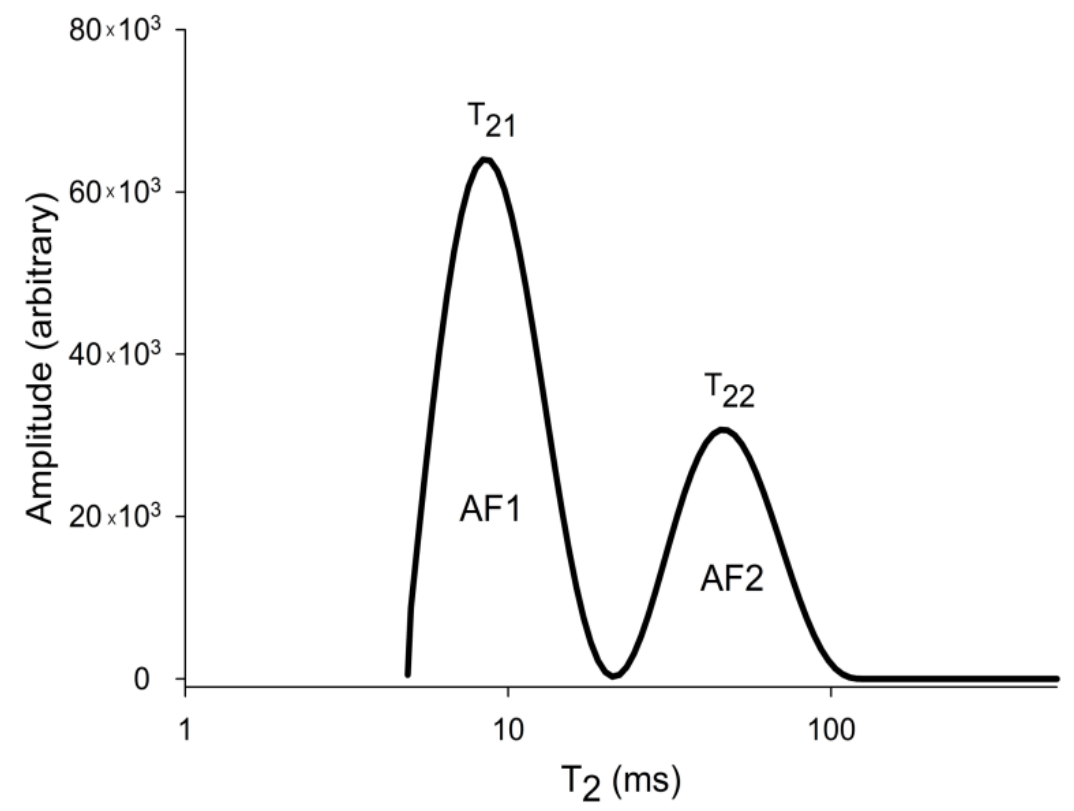

Figure 1. Representative $\mathrm{T}_{2}$ distribution profile of an aged FS cheese at $300 \mathrm{MHz}$. Two proton populations are observed, characterized by geometric mean $T_{2}$ values $\left(T_{21}\right.$ and $\left.T_{22}\right)$ and area fractions of each population (AF1 and AF2).

At high field, diffusive exchange of water and fast chemical exchange between water protons, labile protein protons, and exchangeable protons in small molecules (such as sugars, vitamins, etc.) play a significant role in characterizing the observed relaxation distributions (Figure 1).

It was shown that in skim milk chemical exchange is mainly modulated by whey proteins [40], but in whole milk, the role of fat globules should be taken into account, since fat influences NMR relaxometry results [24]. In addition, it is clear that in cheese fat, protons might reasonably have a role in defining the observed NMR relaxometry profiles [41]. However, in the following discussion, the effect of fat protons on the observed $\mathrm{T}_{2}$ distributions can be reasonably neglected, since fat signal has been saturated by a solvent suppression pulse in the MRI sequence, as previously explained [19].

For each pool, the mean area fractions (AF1 and AF2) and the corresponding $\mathrm{T}_{2}$ values (i.e., the maximum intensity of each peak, $\mathrm{T}_{21}$ and $\mathrm{T}_{22}$ ) were obtained (Table 1 ).

These data are in agreement with previous studies on aged ewe milk cheese and FS PDO [19], which also reported a first $\mathrm{T}_{2}$ population relaxing in the range of 7-12 $\mathrm{ms}$ and a second one at $45-53 \mathrm{~ms}$. The main novelty with respect to the mentioned data consists of the fact that the cheeses analysed in the present work were all made by following the official cheesemaking protocol of FS PDO, except for the thermal treatment of milk. Furthermore, a larger amount of data were used here to preliminarily validate observed data trends; the present results were indeed acquired during a much larger lag time (two production seasons), and two ripening times (105 and 180 days) were compared. Moreover, products from five different artisanal producers plus industrial Fiore Sardo PDO cheeses were analysed. 


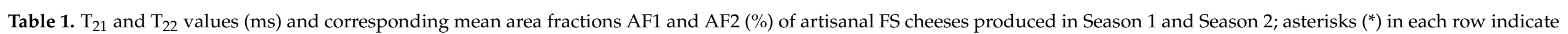
significant differences ( $t$-test, $p<0.05)$ between RC and HTC parameters $\left(\mathrm{T}_{21}\right.$ and $\mathrm{T}_{22}, \mathrm{AF} 1$ and AF2) for each sample $(\mathrm{M}=\mathrm{Mean} ; \mathrm{SD}=\mathrm{Standard}$ Deviation).

\begin{tabular}{|c|c|c|c|c|c|c|c|c|c|c|c|c|c|c|c|c|c|c|c|c|c|c|}
\hline & & & \multicolumn{4}{|c|}{$T_{21}$} & \multicolumn{6}{|c|}{$T_{22}$} & \multicolumn{4}{|c|}{ AF1 } & \multicolumn{6}{|c|}{ AF2 } \\
\hline & & & \multicolumn{2}{|c|}{ RC } & \multicolumn{2}{|c|}{ HTC } & & \multicolumn{2}{|c|}{ RC } & \multicolumn{2}{|c|}{ HTC } & & \multicolumn{2}{|c|}{ RC } & \multicolumn{2}{|c|}{ HTC } & & \multicolumn{2}{|c|}{ RC } & \multicolumn{2}{|c|}{ HTC } & \\
\hline & & & $\mathbf{M}$ & SD & $\mathbf{M}$ & SD & & $\mathbf{M}$ & SD & $\mathbf{M}$ & SD & & $\mathbf{M}$ & SD & $\mathbf{M}$ & SD & & $\mathbf{M}$ & SD & $\mathbf{M}$ & SD & \\
\hline \multirow{9}{*}{ Season 1} & \multirow{4}{*}{105 days } & $\mathrm{S} 2$ & 11.28 & 0.94 & 9.24 & 0.42 & $*$ & 49.05 & 3.84 & 52.15 & 1.85 & $*$ & 0.70 & 0.03 & 0.78 & 0.03 & $*$ & 0.32 & 0.05 & 0.21 & 0.03 & $*$ \\
\hline & & S3 & 10.74 & 0.78 & 9.13 & 0.58 & * & 52.37 & 3.54 & 47.51 & 0.77 & * & 0.82 & 0.02 & 0.82 & 0.02 & & 0.17 & 0.02 & 0.18 & 0.02 & \\
\hline & & $\mathrm{S} 4$ & 8.46 & 0.31 & 8.64 & 0.51 & & 48.33 & 4.15 & 52.67 & 3.12 & $*$ & 0.71 & 0.05 & 0.77 & 0.03 & * & 0.28 & 0.05 & 0.21 & 0.03 & $*$ \\
\hline & & S5 & 8.86 & 0.31 & 9.33 & 0.52 & * & 51.73 & 1.48 & 49.69 & 1.46 & * & 0.77 & 0.02 & 0.81 & 0.02 & * & 0.23 & 0.02 & 0.19 & 0.02 & * \\
\hline & \multirow{5}{*}{180 days } & S1 & 11.94 & 1.17 & 8.76 & 0.24 & * & 47.83 & 3.91 & 48.31 & 2.23 & & 0.52 & 0.09 & 0.62 & 0.03 & * & 0.44 & 0.06 & 0.37 & 0.03 & $*$ \\
\hline & & $\mathrm{S} 2$ & 8.83 & 0.14 & 8.18 & 0.23 & $*$ & 44.92 & 1.38 & 53.34 & 1.05 & $*$ & 0.74 & 0.02 & 0.77 & 0.02 & $*$ & 0.25 & 0.02 & 0.22 & 0.02 & $*$ \\
\hline & & S3 & 10.52 & 0.91 & 7.79 & 0.47 & $*$ & 51.98 & 1.92 & 44.31 & 1.81 & $*$ & 0.79 & 0.01 & 0.79 & 0.03 & & 0.20 & 0.01 & 0.20 & 0.02 & \\
\hline & & $\mathrm{S} 4$ & 9.74 & 1.64 & 7.98 & 0.28 & * & 40.67 & 3.29 & 47.27 & 2.17 & $*$ & 0.56 & 0.03 & 0.70 & 0.03 & * & 0.42 & 0.08 & 0.29 & 0.03 & $*$ \\
\hline & & S5 & 8.50 & 0.31 & 8.80 & 0.74 & $*$ & 49.42 & 1.49 & 46.66 & 1.93 & $*$ & 0.67 & 0.03 & 0.69 & 0.05 & * & 0.32 & 0.03 & 0.30 & 0.05 & * \\
\hline \multirow{9}{*}{ Season 2} & \multirow{4}{*}{105 days } & S1 & 12.70 & 1.60 & 12.70 & 0.69 & & 52.47 & 2.85 & 57.72 & 2.80 & * & 0.68 & 0.05 & 0.78 & 0.04 & * & 0.31 & 0.05 & 0.22 & 0.04 & * \\
\hline & & $\mathrm{S} 3$ & 10.26 & 0.26 & 10.02 & 0.39 & $*$ & 45.93 & 1.05 & 52.22 & 1.46 & $*$ & 0.79 & 0.01 & 0.84 & 0.03 & $*$ & 0.20 & 0.02 & 0.16 & 0.03 & $*$ \\
\hline & & $\mathrm{S} 4$ & 10.20 & 1.48 & 10.49 & 0.31 & & 46.95 & 3.28 & 50.16 & 2.18 & $*$ & 0.67 & 0.07 & 0.79 & 0.01 & * & 0.32 & 0.07 & 0.20 & 0.01 & * \\
\hline & & S5 & 9.29 & 1.08 & 10.74 & 0.42 & $*$ & 43.55 & 3.08 & 53.18 & 1.05 & * & 0.68 & 0.02 & 0.82 & 0.01 & $*$ & 0.31 & 0.02 & 0.17 & 0.01 & $*$ \\
\hline & \multirow{5}{*}{180 days } & S1 & 9.08 & 0.18 & 8.82 & 0.50 & * & 49.26 & 2.67 & 52.37 & 4.38 & * & 0.62 & 0.04 & 0.78 & 0.06 & * & 0.37 & 0.04 & 0.21 & 0.06 & $*$ \\
\hline & & $\mathrm{S} 2$ & 9.94 & 0.66 & 9.21 & 0.44 & * & 53.10 & 2.35 & 52.33 & 1.93 & & 0.72 & 0.05 & 0.80 & 0.03 & $*$ & 0.27 & 0.05 & 0.19 & 0.03 & $*$ \\
\hline & & S3 & 10.39 & 0.50 & 8.78 & 0.35 & $*$ & 50.97 & 1.01 & 52.90 & 1.61 & $*$ & 0.72 & 0.03 & 0.76 & 0.03 & $*$ & 0.27 & 0.03 & 0.23 & 0.03 & $*$ \\
\hline & & S4 & 9.09 & 0.74 & 8.31 & 0.51 & $*$ & 50.87 & 3.87 & 48.03 & 3.28 & $*$ & 0.68 & 0.05 & 0.73 & 0.03 & $*$ & 0.31 & 0.05 & 0.26 & 0.03 & $*$ \\
\hline & & S5 & 14.55 & 2.24 & 10.07 & 0.38 & $*$ & 44.94 & 3.34 & 53.00 & 1.14 & * & 0.57 & 0.03 & 0.72 & 0.02 & * & 0.42 & 0.03 & 0.27 & 0.02 & * \\
\hline
\end{tabular}


Statistical analysis of MRI relaxometry values (Table 1) indicated significant differences in $T_{21}$ and $T_{22}$ values between RC and HTC cheeses. Evaluation of AF suggested the same consistent trend, with a significantly larger amount of protons in the faster relaxing population (AF1) in HTC cheeses than in RC. This is in quite good agreement with previous results on MRI relaxometry of heat-treated milk cheeses [19] and on the sensorial evaluation of Fiore Sardo cheese, suggesting that sensorial attributes and relaxometric features may correlate to each other and that they are both more appreciably affected by milk properties and cheesemaking processes than ripening [11].

Since for each production reported in Table 1 (S1-S5) the same milk was used, the manufacturing process was carried out by the same dairyman, and ripening time was exactly the same for both treatments (RC and HTC), the only factor that accounts for the observed relaxometry differences is milk thermisation.

From a previous investigation [19] and in accordance with pertinent literature [42-44], the fast relaxing proton pool (described by the pair $\mathrm{T}_{21}$; AF1) can be associated with a fraction of water molecules strongly interacting with protons and entrapped in the para-casein network (protein hydration water); the slower population $\left(\mathrm{T}_{22} ; \mathrm{AF} 2\right)$ can be associated with more mobile water molecules, which less strongly interact with the cheese protein network (which is sometimes referred to as bulk or "free" water).

Several different mechanisms may reasonably affect observed transverse relaxation rates. The first mechanism is related to an altered proportion between more mobile (free) water pools and water in the vicinity of the protein surface (hydration water), which is reasonably well described by AF1 $[16,19,45]$. This mechanism is in turn modulated by the diffusive exchange rate between water entrapped within the protein network of cheese, confined in cheese holes or pores and hydration water, and chemical exchange $[39,46]$ between water protons and labile protein protons (mainly whey proteins [40]). The second mechanism involves internal water molecules in casein micelles, sometimes referred to as "bound" water molecules, which represent structural water molecules in the internal cavities, engaged in slowly modulated intermolecular dipole couplings with protein protons [46]. A significant effect of these "bound" water molecules on the observed proton transverse relaxation rate has been already suggested in dairy systems [40]. A third mechanism is explained by considering changes in the correlation time of macromolecules as a function of the ripening and processing methods [16,47]. Finally, relevant contribution could be expected from the mineral equilibrium of milk and its effect on micelles hydration. Equilibrium between colloidal (solid) and soluble calcium phosphate is in fact affected by temperature $[48,49]$; this has also been observed in Fiore Sardo cheeses manufactured from raw or heat-treated milk [6]. In particular, higher total calcium was found in Fiore Sardo produced from raw milk than from thermised milk, and it was hypothesized that mineral equilibrium in milk was shifted from soluble calcium to insoluble colloidal calcium as an effect of a high treatment temperature, leading to a higher retention of calcium in Fiore Sardo from raw milk [6]. Micellar calcium phosphate is a highly hydrated colloid, which greatly influences proton transverse relaxation. Ca and $\mathrm{P}$ association to casein and micelle hydration are strictly related phenomena, having a marked effect of NMR transverse relaxation of protons $[40,48,49]$. Heat treatment of milk was in fact found to cause precipitation of calcium phosphate and correspondingly affect proton $\mathrm{T}_{2}$ [48].

\subsection{MRI Analysis of Dataset 2}

Industrial Fiore Sardo samples were characterized by the presence of two water proton pools, in agreement with results on artisanal samples RC and HTC discussed above. Mean area fractions (AF1 and AF2) and $T_{2}$ values $\left(T_{21}\right.$ and $\left.T_{22}\right)$ are shown in Table 2.

Both relaxation time constants $\mathrm{T}_{2}$ and area values AF were consistent with the HTC artisanal cheeses analysed in Dataset 1, with the exception of samples from the maturer industry (I12, I13).

Both the increase of AF1 and the decrease of $\mathrm{T}_{21}$ are the result of a strong interaction between water protons and the para-casein protein network of cheese, i.e., of cheese protein 
hydration. From a certain point of view, AF1 more directly describes the level of protein hydration, being determined by the amount of protons in this pool. However, a decrease of the $T_{21}$ value, being the result of the weighted average between the (long) $T_{2}$ of protons in free water pools and that (very short) of labile protein protons, characterized by a different chemical shift and affected by the typically long reorientational times of biological macromolecules, can be indirectly influenced by the amount of protein hydrating water.

Aiming to find suitable and objective descriptors of the relaxometric changes induced in cheese by milk thermisation, we define a new parameter, namely the Score ( $\dot{\mathrm{S}})$ factor, as a representative indicator of the state of cheese microstructure. The Score (Ș) is defined as follows:

$$
S=\mathrm{T}_{21} / \mathrm{AF} 1
$$

where $\mathrm{T}_{21}$ and $\mathrm{AF} 1$ are the relaxation time and the area fraction of population 1, respectively, of the MRI T 2 distribution profile (Figure 1). Based on what was discussed above, the lower the Score, the more affected cheese microstructure is by milk thermisation. Correspondingly, the higher the Score, the less influenced are cheese proteins by any thermal effect on milk, i.e., milk can be considered as raw or untreated.

The calculated Ș values (Season 1 and Season 2) are presented in Figure 2.

Even at first glance, two considerations can be made when observing Figure 2: first, thermisation of milk in HTC cheeses (red symbols) leads to a reduction of Ș with respect to their raw RC counterparts (blue symbols); second, RC samples show much higher $\stackrel{S}{\text { S }}$ variability than their HTC counterparts.

Table 2. $\mathrm{T}_{21}$ and $\mathrm{T}_{22}$ values and correspondent mean area fractions AF1 and AF2 of industrial FS cheeses (M = Mean; $\mathrm{SD}=$ Standard Deviation).

\begin{tabular}{ccccccccc}
\hline & \multicolumn{2}{c}{$\mathbf{T}_{\mathbf{2 1}}$} & \multicolumn{2}{c}{$\mathbf{T}_{\mathbf{2 2}}$} & \multicolumn{2}{c}{ Area 1 } & \multicolumn{2}{c}{ Area 2 } \\
\hline I1 & $\mathbf{M}$ & $\mathbf{S D}$ & $\mathbf{M}$ & $\mathbf{S D}$ & $\mathbf{M}$ & $\mathbf{S D}$ & $\mathbf{M}$ & SD \\
\hline I2 & 10.032 & 0.056 & 52.046 & 0.141 & 0.891 & 0.001 & 0.102 & 0.001 \\
\hline I3 & 9.214 & 0.038 & 45.078 & 0.035 & 0.814 & 0.001 & 0.178 & 0.001 \\
\hline I4 & 8.523 & 0.030 & 29.646 & 0.043 & 0.871 & 0.002 & 0.120 & 0.002 \\
\hline I5 & 8.018 & 0.024 & 51.936 & 0.047 & 0.697 & 0.002 & 0.294 & 0.002 \\
\hline I6 & 8.742 & 0.020 & 44.319 & 0.042 & 0.836 & 0.001 & 0.156 & 0.001 \\
\hline I7 & 9.318 & 0.023 & 51.352 & 0.133 & 0.858 & 0.012 & 0.130 & 0.000 \\
\hline I8 & 9.462 & 0.022 & 51.054 & 0.058 & 0.813 & 0.001 & 0.180 & 0.000 \\
\hline I9 & 9.463 & 0.018 & 51.058 & 0.037 & 0.813 & 0.001 & 0.180 & 0.001 \\
\hline I10 & 9.466 & 0.114 & 48.470 & 0.292 & 0.876 & 0.002 & 0.117 & 0.002 \\
\hline I11 & 9.188 & 0.047 & 46.314 & 0.131 & 0.843 & 0.001 & 0.150 & 0.001 \\
\hline I12 & 7.702 & 0.098 & 34.887 & 0.084 & 0.575 & 0.004 & 0.415 & 0.004 \\
\hline I13 & 7.301 & 0.029 & 34.772 & 0.013 & 0.545 & 0.002 & 0.442 & 0.002 \\
\hline
\end{tabular}

Cheeses from one producer (S5) showed subtle, though significant, NMR relaxometry changes upon milk thermisation (blue and red circles are superimposed in Figure 2). In fact, for producer $\mathrm{S} 5$, both $\mathrm{AF} 1$ and $\mathrm{T}_{21}$ values always showed only slightly significant changes when RC and HTC cheese samples were compared at 105 days of ripening and at 180 days in Season 1 (Table 1). It should be considered that, at the shortest ripening time allowed for Fiore Sardo commercialization (105 days of ripening), the effect of water redistribution and protein hydration might still be not sufficient in order to clearly discriminate RC from HTC. In these cases, NMR relaxometry analysis should be replicated after a longer ripening time to obtain clearer results (Figure $2 b$,d). If a discrimination between RC and HTC is still not present at six months of ageing, then very likely milk has been overheated to some extent, 
and cheese features are not comparable to raw milk cheeses anymore. This result can be explained by assuming that, though thermisation was not intentionally performed in S5 production, raw milk was likely subjected to excessive heat before rennet addition. In fact, it is worth recalling here that, even at an artisanal level, milk is always treated to some extent during cheesemaking, since rennet is usually added when milk reaches, upon heating, a temperature in the range of approximately 35 and $38^{\circ} \mathrm{C}$, depending on the season, site, climate and usual practices of production. Among Fiore Sardo artisan producers, milk heating, according to traditional cheesemaking processes, is mostly carried out by directly warming up (often by means of an industrial stove gas cooker) a copper boiler containing raw milk. In some other cases, but still at artisanal level, more modern stainless steel multipurpose cheesemaking tanks are used to heat milk by means of water vapour in somewhat larger dairy plants. Only bigger industrial dairy plants adopt flow pasteurizers equipped with sophisticated plate heat exchanger modules, in order to perform more controlled high temperature-short time heat treatments. This consideration could explain the very subtle difference between the NMR relaxometry parameters of RC and HTC cheeses at 105 days and 180 days of ripening in S5 samples.

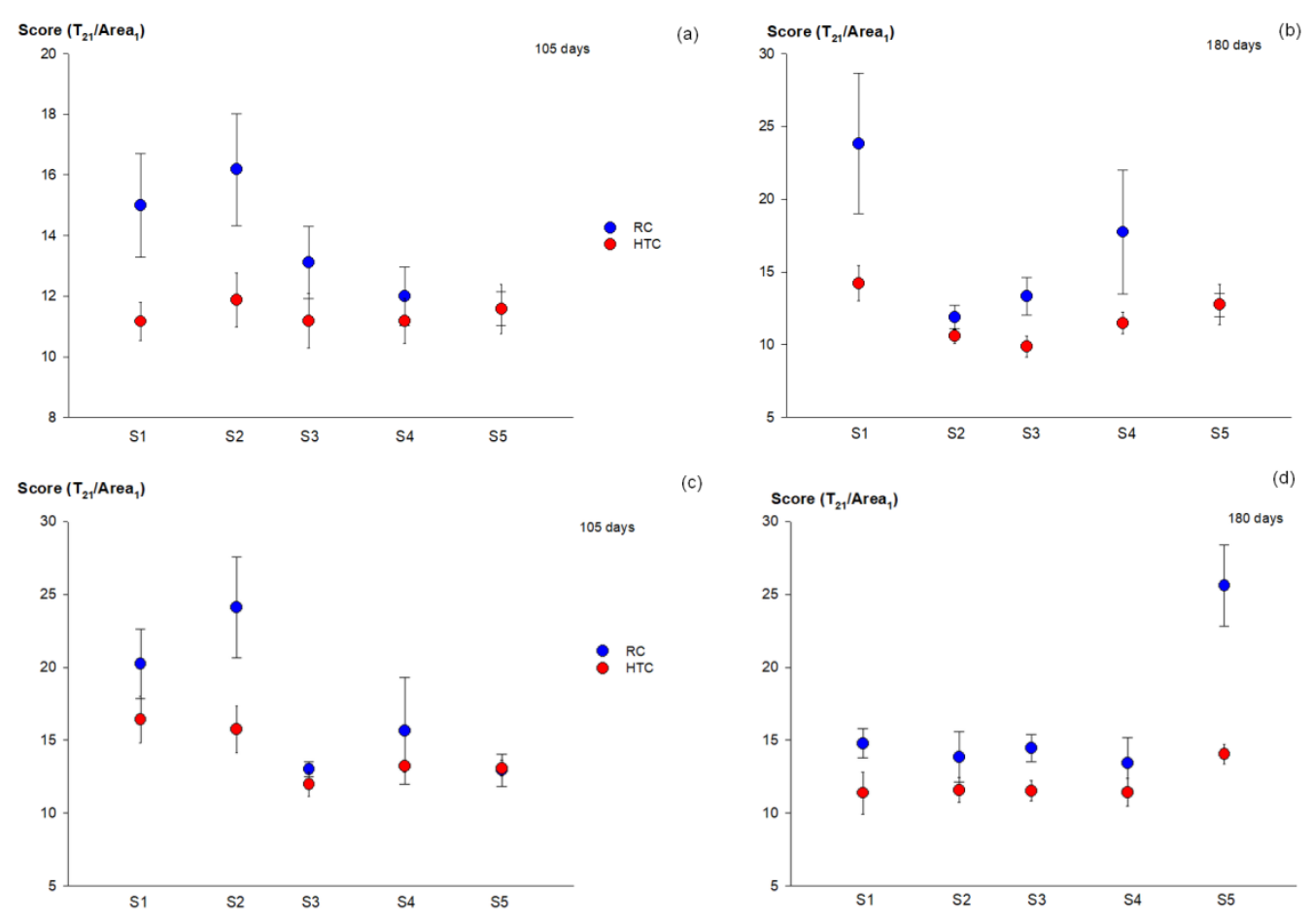

Figure 2. Score factors (Ș் of Fiore Sardo cheeses from Dataset 1: 105 days (a) and 180 days (b) of ripening, Season 1 (March-April 2019); 105 days (c) and 180 days (d) of ripening, Season 2 (JanuaryFebruary 2020). Blue circles represent samples made from raw milk (RC) and red circles represent cheeses made starting from heat-treated milk (HTC).

Notably, S5 and other shepherd's productions show superimposed error bars in Figure 2. This is mainly due to the large variability of $R C$ and to similar technological considerations as already discussed for S5.

As explained above, the score value Ș represents and describes the status of water molecules more tightly interacting with the paracasein network of cheese. Low score values (i.e., higher $\mathrm{AF} 1$ and / or lower $\mathrm{T}_{21}$ ) indicate a high degree of protein hydration, arising from either ripening [16,45] or from the effect of heat treatments [19]. For cheeses having the same ripening time, the effect of the thermal treatment of milk on the following processing steps [5] dominates relaxation.

In fact, previous studies carried out at variable fields by fast field cycling NMR relaxometry (FFC-NMR) have demonstrated that the hydration of cheese proteins is affected 
by cheese ageing $[45,47]$. Further FFC-NMR studies have demonstrated that, for a given ageing time, cheese protein hydration can also be significantly affected by the different processing methods preceding cheese maturation [16]. As discussed above, two similar Fiore Sardo cheeses, which only differ in their heat treatment of milk, also differ in their NMR relaxometry characteristics. The reasons for the observed relaxometry differences can be found in cheese microstructure (such as fractal dimension, protein proton to water proton ratio, water mobility and protein hydration) [16].

The variability of Score values (Ș) within each group and among groups of cheeses is presented in the form of box plots in Figure 3. Standard deviations of RC of shepherds (blue boxplot) were generally larger than the other groups. Median values of RC are higher than all other groups, followed by maturer cheeses, HTC and industrial samples, with the latter showing the lowest median values. RC samples show considerably higher interquartile range than HTC and much larger whiskers. This could be reasonably ascribed to both the effect of the artisanal manufacturing process on cheese microstructure and to the microbiological complexity of the systems arising from the use of raw milk. In fact, while artisanal cheesemaking entails mainly manual practices, industrial production implies more standardized protocols and a higher degree of process automation. In addition, previous reports on raw and heat-treated milk cheeses demonstrated a larger variability of raw-milk cheeses than pasteurized-milk cheese counterparts, and it was suggested that the effect of heat on milk proteins, indigenous enzymes and microbial flora of milk may reduce variability, resulting in a more homogeneous peptide profile, sensory properties and NMR relaxation parameters for pasteurized-milk cheese [19,50,51].

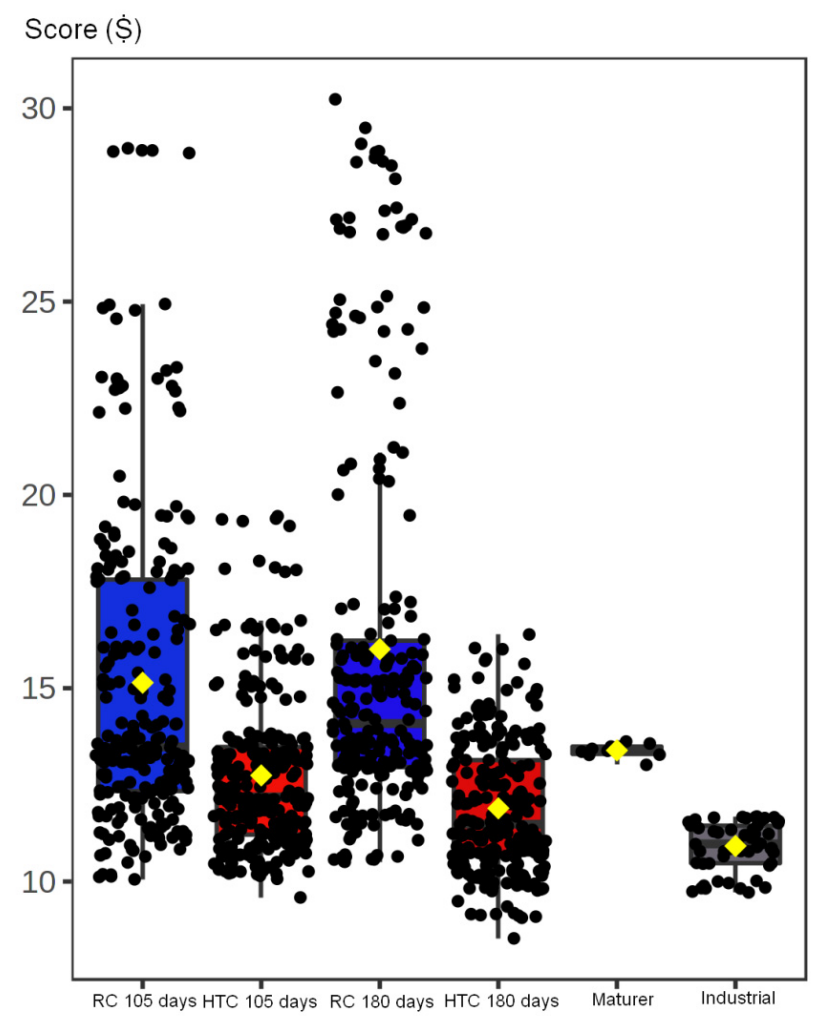

Figure 3. Box plots of the Score values $(\dot{S})$ of each group of cheeses (RC, HTC, industrial and maturer cheeses).

Differences in the manufacturing process are reflected in different physico-chemical and sensory features, resulting in the distinctiveness of each wheel from the same shepherd. While heating milk to $35-38{ }^{\circ} \mathrm{C}$, necessary for a proper action of rennet, is usually not strictly standardized in terms of temperature control, industrial processing is carefully controlled. Mild thermal treatments of raw milk, typical of artisanal practices, allow for the 
preservation of the microorganisms that represent a sort of fingerprint of each shepherd's production. The development of indigenous milk microflora and the related molecular changes (e.g., changes in $\mathrm{pH}$, proteolysis and lipolysis during ripening, etc. [5]) occurring during the following processing steps, together with the exclusively manual manufacturing operations on curd, are reflected in the microstructural, molecular and sensory properties of the final cheese, making every wheel a unique product. That is why artisanal Fiore Sardo PDO cheeses are very different from each other, being strongly linked to the territory and to the specific production practices. It is interesting to note, in this regard, that milk and curd handling practices for making Fiore Sardo are passed down from generation to generation and often differ from each other in subtle, but likely relevant, details. On the other hand, when heat is applied to the same milk, though (almost) the same manufacturing practices are carried out by the same cheesemongers, part of the characteristic microflora is depleted and milk functionality is altered [51,52]. The Ș data distribution in HTC cheeses indeed indicated a reduced heterogeneity in comparison to RC. The box plot of industrial cheeses more clearly shows that the spreading of $\dot{S}$ values is considerably reduced and very narrow in comparison to both RC and HTC. This is mostly ascribable to industrial practices, where cheesemaking is strictly controlled and standardized in terms of both microbiological conditions and technological operations. It is worth noting that industrial Fiore Sardo samples were purchased from different industrial producers, so the observed low interquartile range should be considered quite representative of the standardization of the industrial production in the market and cannot be ascribed to a specific producer.

Mean and standard deviations of Score values $\grave{S}$ for all groups of samples (RC, HTC, I and maturer), together with their statistical significances, are presented in Table 3.

Table 3. Statistical comparison of Score $(\dot{S})$ values (ANOVA, $p<0.05$ ) of the four groups of Fiore Sardo samples, namely RC, HTC (produced in Season 1 and Season 2), maturer and industrial cheeses. Each shepherd production (RC and HTC) was individually compared to maturer and industrial cheeses; data are expressed as Mean \pm Standard Deviation; means sharing the same superscript letters are not significantly different from each other; the letter "a" is assigned to the higher mean.

\begin{tabular}{|c|c|c|c|c|c|c|}
\hline & & & RC & HTC & Maturer & Industrial \\
\hline \multirow{4}{*}{ S1 } & \multirow{2}{*}{ Season 1} & 105 days & $14.99 \pm 1.70^{\mathrm{a}}$ & $11.17 \pm 0.62^{c}$ & $13.39 \pm 0.18^{b}$ & $10.92 \pm 0.62^{c}$ \\
\hline & & 180 days & $23.83 \pm 4.83^{\mathrm{a}}$ & $14.22 \pm 1.22^{b}$ & $13.39 \pm 0.18^{b}$ & $10.92 \pm 0.62^{c}$ \\
\hline & \multirow{2}{*}{ Season 2} & 105 days & $20.25 \pm 2.38^{a}$ & $16.43 \pm 1.60^{b}$ & $13.39 \pm 0.18^{c}$ & $10.92 \pm 0.62^{d}$ \\
\hline & & 180 days & $14.78 \pm 1.00^{\mathrm{a}}$ & $11.38 \pm 1.45^{c}$ & $13.39 \pm 0.18^{b}$ & $10.92 \pm 0.62^{c}$ \\
\hline \multirow{4}{*}{$\mathrm{S} 2$} & \multirow{2}{*}{ Season 1} & 105 days & $16.18 \pm 1.85^{a}$ & $11.87 \pm 0.90^{c}$ & $13.39 \pm 0.18^{b}$ & $10.92 \pm 0.62^{d}$ \\
\hline & & 180 days & $11.90 \pm 0.81^{b}$ & $10.57 \pm 0.48^{c}$ & $13.39 \pm 0.18^{a}$ & $10.92 \pm 0.62^{c}$ \\
\hline & \multirow{2}{*}{ Season 2} & 105 days & $24.10 \pm 3.44^{\mathrm{a}}$ & $15.74 \pm 1.59^{b}$ & $13.39 \pm 0.18^{c}$ & $10.92 \pm 0.62^{d}$ \\
\hline & & 180 days & $13.86 \pm 1.74^{a}$ & $11.58 \pm 0.86^{b}$ & $13.39 \pm 0.18^{a}$ & $10.92 \pm 0.62^{c}$ \\
\hline \multirow{4}{*}{ S3 } & \multirow{2}{*}{ Season 1} & 105 days & $13.12 \pm 1.19^{a}$ & $11.19 \pm 0.90^{b}$ & $13.39 \pm 0.18^{a}$ & $10.92 \pm 0.62^{b}$ \\
\hline & & 180 days & $13.33 \pm 1.29^{a}$ & $9.86 \pm 0.73^{c}$ & $13.39 \pm 0.18^{a}$ & $10.92 \pm 0.62^{b}$ \\
\hline & \multirow{2}{*}{ Season 2} & 105 days & $13.02 \pm 0.51^{a}$ & $11.98 \pm 0.82^{b}$ & $13.39 \pm 0.18^{a}$ & $10.92 \pm 0.62^{c}$ \\
\hline & & 180 days & $14.47 \pm 0.94^{\mathrm{a}}$ & $11.53 \pm 0.70^{c}$ & $13.39 \pm 0.18^{b}$ & $10.92 \pm 0.62^{d}$ \\
\hline \multirow{4}{*}{$\mathrm{S} 4$} & \multirow{2}{*}{ Season 1} & 105 days & $12.00 \pm 0.97^{b}$ & $11.18 \pm 0.75^{c}$ & $13.39 \pm 0.18^{a}$ & $10.92 \pm 0.62^{c}$ \\
\hline & & 180 days & $17.74 \pm 4.27^{\mathrm{a}}$ & $11.48 \pm 0.75^{b c}$ & $13.39 \pm 0.18^{b}$ & $10.92 \pm 0.62^{c}$ \\
\hline & \multirow{2}{*}{ Season 2} & 105 days & $15.65 \pm 3.68^{a}$ & $13.23 \pm 0.40^{b}$ & $13.39 \pm 0.18^{b}$ & $10.92 \pm 0.62^{c}$ \\
\hline & & 180 days & $13.41 \pm 1.77^{\mathrm{a}}$ & $11.42 \pm 0.96^{b}$ & $13.39 \pm 0.18^{a}$ & $10.92 \pm 0.62^{b}$ \\
\hline \multirow{4}{*}{ S5 } & \multirow{2}{*}{ Season 1} & 105 days & $11.58 \pm 0.56^{\mathrm{b}}$ & $11.57 \pm 0.81^{\mathrm{b}}$ & $13.39 \pm 0.18^{a}$ & $10.92 \pm 0.62^{c}$ \\
\hline & & 180 days & $12.74 \pm 0.81^{\mathrm{a}}$ & $12.76 \pm 1.39^{a}$ & $13.39 \pm 0.18^{a}$ & $10.92 \pm 0.62^{b}$ \\
\hline & \multirow{2}{*}{ Season 2} & 105 days & $12.93 \pm 1.10^{\mathrm{a}}$ & $13.08 \pm 0.53^{a}$ & $13.39 \pm 0.18^{a}$ & $10.92 \pm 0.62^{b}$ \\
\hline & & 180 days & $25.61 \pm 2.79^{a}$ & $14.05 \pm 0.69^{b}$ & $13.39 \pm 0.18^{b}$ & $10.92 \pm 0.62^{c}$ \\
\hline
\end{tabular}


In general, ANOVA results suggested a consistent differentiation among the four groups of cheeses. Industrial Fiore Sardo showed the lowest Ș values in all comparisons, except for one case (i.e., S3 180 days, Season 1), which had Ș values higher than HTC only. RC often had significantly higher $S$ values than other groups of cheeses, except for two cases (i.e., S4 and S5, 105 days, Season 1), when maturer cheeses showed higher Ș. This result can be explained by considering that maturer cheeses were purchased after approximately 6-8 months of ripening. In some other cases, $\mathbf{S}$ values were comparable for RC, HTC and maturer cheeses. Statistical comparison of HTC and industrial cheeses

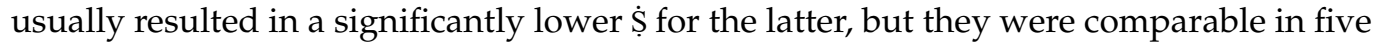
cases. Maturer samples were never comparable to industrial samples.

Based on the aforementioned statistical evaluations, some conclusions can be drawn on the manufacturing process of each group of samples and on the quality features of the resulting cheeses. RC and HTC were entirely produced following artisanal procedures. Maturer cheeses share the same artisanal processing but were ripened in industrial-like conditions, in refrigerated cellars with controlled humidity and temperature. Despite different ripening conditions, RC and maturer cheeses were described by very similar $\dot{S}$ values, clearly suggesting that technological transformations that precede ripening confer to cheeses a common relaxometric behaviour described by comparable Ș. RC and maturer cheeses were generally described by higher $\mathbf{S}$ than industrial cheeses, although ANOVA suggested that RC, HTC and maturer cheeses can still differ to some extent among each other in terms of the new quality-related parameter, Ș. Since the RC and HTC cheeses of each shepherd were technologically processed in the same way, the decrease in Ș observed between RC and HTC (Figure 3), supported by ANOVA comparisons (Table 3), can be reasonably and solely related to the application of a heat treatment of the milk. On the other hand, industrial samples, besides having a much narrower Ș variability (Figure 3) clearly exhibited considerably and significantly lower $\dot{S}$ values with respect to the other three groups of cheeses. These relaxometric behaviours could be reasonably associated with the features of industrial productions, for which milk and curd processing and handling are more mechanized and standardized, ensuring more uniform features in the final products, as previously reported [16]. Moreover, a contribution to the low Ș may arise from the application of a heat treatment to the milk that is consistent with common industrial processing practices, as realistically suggested [12-15]. Interestingly, the discrimination ability of $\dot{S}$ and its potential in identifying relevant quality features of Fiore Sardo cheeses does not seem to be affected by different seasons of lactation (i.e., to milk compositional quality), being instead more strictly related to milk processing. This consideration derives from the significant statistical differences among the four groups of samples, regardless the season (Figure 3, Table 3). As far as ripening conditions are concerned, the significant role of ripening cannot be excluded. However, the effect of ripening conditions seems to be less influential than the milk and curd processing practices preceding cheese ageing. This makes NMR relaxometry a suitable analytical tool for characterizing the effect of heat treatments of milk on quality features of Fiore Sardo cheese.

\subsection{Moisture Content}

The moisture content of all cheese samples are reported in Table S2.

Moisture content was not influenced by heat treatment, indeed showing no consistent trend in RC and HTC samples. This is in contrast to MRI parameters, which showed consistent changes according to heat treatments. Since MRI parameters $T_{21}$ and AF1 could be considered representative of the portion of water in the samples, such changes could not be related to total moisture content [19]. In addition, for industrial samples, no noticeable correlation was found between MRI parameters and moisture content.

Water status can be described at different scales of investigation-at a macroscopic level by moisture content and at a molecular level by MRI-and can lead to different information about the analyzed matrix. Moisture content is representative of the extractable water molecules by drying in certain conditions and is among the most common parameters 
used to describe food quality. However, it should not be considered as an exhaustive parameter as it does not give any information on water proton pools in the system (if any) and their interactions with the protein matrix in cheese [53].

\subsection{Image Analysis of Fiore Sardo Pictures and MRI Images}

Representative pictures of the visual appearance of RC and HTC at the minimum allowed ripening time for Fiore Sardo PDO (i.e., 105 days) are shown in Figure 4.

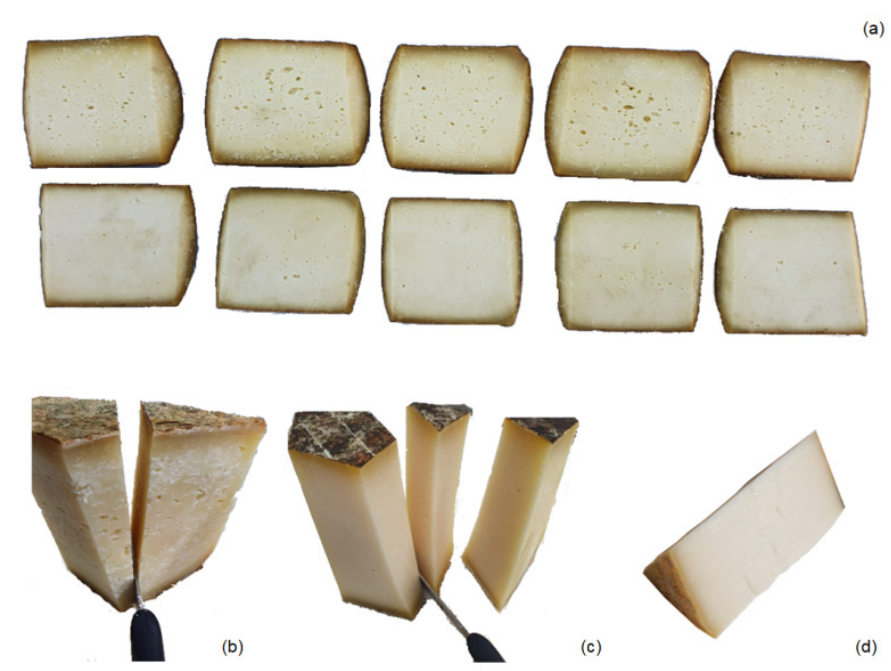

Figure 4. Representative images of the visual appearance of RC, HTC and industrial samples: Producer S1, Season 2, 105 days of ripening, Fiore Sardo from raw milk (upper row) and from heat-treated milk (lower row) (a); details of RC (b) and HTC (c) samples ripened 105 days upon cutting; industrial Fiore Sardo purchased from a local market, with at least 105 days of ripening (d).

Even at first sight, RC, HTC and industrial cheeses appear very different from each other. The HTC samples surface appears more homogeneous, smoother and with fewer holes, while RC cheeses are more grainy, friable and show more and bigger holes. When cut with a knife, RC cheeses are prone to easily break and crumble, while HTC appear more creamy and can be cut very easily and without breaking into pieces.

The different visual appearances of HTC samples with respect to RC cheeses is reasonably ascribable to the modifications resulting from the heat treatment of milk, which is known to have, in Fiore Sardo PDO, multiple consequences on cheese composition, microstructure and texture, which in turn affect appearance and sensory properties in general [6,10,52].

In general, MRI images confirmed, by a non-invasive approach, what already appeared at a first visual inspection of samples. RC cheeses exhibited a coarser paste, often with multiple cracks and holes, while HTC samples exhibited a smoother and more homogenous paste (Figure S5).

Two kinds of scientific considerations can be made based on the MRI images acquired. On one hand, as discussed above, MRI images give relaxometric information that is able to provide useful insights on the state of biopolymers and on the mobility of the system at molecular level. On the other hand, important information can be derived from the texture of MRI images by performing a detailed image analysis.

In recent years, image analysis techniques rapidly emerged not only at the academic level but also as rapid, economic, consistent and objective inspection techniques in the agricultural and food industry $[54,55]$. In particular, for the dairy industry sector, modern computer vision and image analysis methods have been used to evaluate cheese external or internal quality attributes such as colour, shape, texture, amount and distribution of added ingredients or production defects [56-58]. 
In this study, we pave the way for a deep-learning-based method for the classification of Fiore Sardo cheese images. The method consists of using data collected both from MRI and from a computer vision system based on photographic images taken with a smartphone camera. Deep learning is a subfield of artificial intelligence (AI) concerned with specific algorithms for thinking simulations and data processing inspired by the neurons of the brain [31]. Deep-learning-based image classification has proven to be highly effective in image classifying, object detection and other computer vision related problems $[59,60]$.

All pre-trained DNN models run well in the open web GPU_Google colab service, with compatible and relatively short training times. For both MRI and photo datasets, the best classification result was achieved by the SqueezeNet model (Tables S3 and S4). In particular, for the $\mathrm{T}_{2}$ weighted MRI images, the SqueezeNet model exhibits a training accuracy from $93 \%$ to $98 \%$, with the highest validation score (100\%) (Table S3). As far as the photo dataset is concerned, SqueezeNet shows a training accuracy of $96 \%$, with the same validation of $100 \%$ (Table S4).

The other pre-trained models (ResNet, AlexNet, VggNet, Densenet and Inceptionnet) also exhibit satisfactory performance results, ranging from a minimum of $72 \%$ to a maximum of $92 \%$, with related validation ranging from $77 \%$ to $100 \%$ (Tables S3 and S4).

We propose here an IA approach to classify photos and $\mathrm{T}_{2}$ weighted MRI images of Fiore Sardo cheese made with raw or thermised milk, by applying a deep neural network (DNN), which includes several chained layers of processing between the input (photos or MRI images) and the output (classification/label of the input image).

As with most state-of-the-art IA methods, deep learning models usually require fitting thousands or millions of input data; thus, their application to those studies where the sample size is limited appears prohibitive. To address this challenge, the deep transfer learning approach offers a more suitable alternative. Transfer learning is the method by which the model uses the knowledge gained during the training of a relatively large dataset in a different but related problem (i.e., image classification and recognition). During the transfer learning process, only the selected classifier(s) is trained in the new network, while the features learned from the large dataset are transferred. Therefore, with the deep transfer learning approach, we do not need to retrain the entire network for a new dataset, thus allowing the training of deep learning models with relatively few data, reduced computational power and less training time [61].

With the main disadvantage of the present study being the relatively low number of available cheese samples, compared to the large data size usually needed for training deep learning frameworks, we chose to transfer the learning technique by testing six pre-trained DNN frameworks (ResNet, AlexNet, VggNet, SqueezeNet, DenseNet and Inception-Net), a widely used approach for addressing classification and image recognition challenges of MRI data.

In the end, all tested pre-trained DNNs yielded promising performances, giving an average classification accuracy of over $72 \%$ and over $93 \%$ in particular for the best performing SqueezeNet model (Tables S3 and S4). We did not perform further accuracy tests of the DNN pre-trained model in this study; however, we are proposing to implement and optimize this model in a dedicated study when more data are available.

\section{Conclusions}

Our data demonstrate that NMR relaxometry is able to assess molecular mobility changes induced in cheese by the most common industrial thermal treatments carried out on milk. In the present work, the experimental plan was optimized to exclude possible confounding factors. The same milk was used for producing both raw-milk or thermisedmilk cheese. Moreover, analyses were repeated in different seasons, and the products from different producers were compared. Results were compared with a selection of industrial Fiore Sardo cheeses purchased in the local market.

NMR relaxometry data of Fiore Sardo cheese indicated the presence of two water populations, described by characteristic $\mathrm{T}_{2}$ relaxation times and area fractions. In particular, 
the first and fastest relaxing population showed a good predictive value. In order to obtain a relaxometric descriptor of FS cheese microstructure and molecular mobility, a new qualityrelated parameter was introduced, namely the Score factor (Ș). The Ș describes cheese in relation to the hydration status of the casein network and the state of the water-fat-protein network in cheese. We were able to discriminate FS cheeses produced from raw (RC) and heat-treated milk (HTC), with the latter exhibiting a lower ș, indicating an enhanced hydration of the casein network. Industrially manufactured FS cheeses had generally lower $\grave{S}$ values than RC and HTC. Samples from the maturer industry, which buys cheeses before ripening and ages cheeses in industrial-like refrigerated cellars, showed similar values to artisanal cheeses, suggesting that NMR relaxometry is more sensitive to changes occurring in the cheesemaking steps preceding ripening. A further discriminative approach was finally carried out by processing acquired MRI images and photos with an IA method based on pre-trained deep learning algorithms. Preliminary classification results suggested that this innovative approach is promising in providing suitable discrimination between RC and HTC Fiore Sardo cheese.

Supplementary Materials: The following are available online at https:/ /www.mdpi.com/article/10 .3390/dairy2020023/s1, Figure S1: sample production and sampling scheme for MRI analysis, Figure S2: MRI sample preparation scheme, Figure S3: Computer Vision System (CVS) for photographic analysis, Figure S4: Image Dataset Directory and File Structure used, Figure S5: Representative $T_{2}$ weighted MRI images of Fiore Sardo cheeses, Table S1: Production of FS cheeses and datasets, Table S2: Moisture content data of cheeses, Table S3: Performance and classification results of pre-trained DL frameworks on MRI images, Table S4: Performance and classification results of pre-trained DL frameworks on photographic images.

Author Contributions: Conceptualization, R.A.; Methodology, R.A., E.C. and R.M.; Software, E.C. and R.M; Formal Analysis, R.A., E.C. and R.M; Investigation, R.A., E.C. and R.M.; Data Curation, E.C. and R.M.; Writing - Original Draft Preparation, R.A., E.C. and R.M.; Writing-Review and Editing, R.A., E.C. and R.M.; Visualization, E.C. and R.M.; Supervision, R.A.; Funding Acquisition, R.A.; Project Scientific Coordination, R.A. All authors have read and agreed to the published version of the manuscript.

Funding: This research was funded by the Sardinia Regional Government by means of Sardegna Ricerche (art 9, L.R. n. 15, 17.11.2010).

Data Availability Statement: The data presented in this study are available on request from the corresponding author.

Conflicts of Interest: The authors declare no conflict of interest. The funders had no role in the design of the study; in the collection, analyses, or interpretation of data; in the writing of the manuscript, or in the decision to publish the results.

\section{References}

1. European Commission. Quality Schemes Explained. Available online: https://ec.europa.eu/info/food-farming-fisheries/foodsafety-and-quality / certification/quality-labels/quality-schemes-explained (accessed on 16 February 2021).

2. European Commission eAmbrosia-The EU Geographical Indications Register. Available online: https://ec.europa.eu/info/ food-farming-fisheries/food-safety-and-quality/certification/quality-labels/geographical-indications-register/\# (accessed on 11 April 2021).

3. Sardo, P.; Barletta, M. European Designations between Identity Values and Market. 2019. Available online: https://www. slowfood.com/wp-content/uploads/2019/09/European-designations-between-identity-values-and-market_ENG.pdf (accessed on 26 February 2021).

4. Fox, P.; McSweeney, P.; Cogan, T.; Guinee, T. Cheese-Chemistry, Physics and Microbiology, 3rd ed.; Guinee, P., Fox, P., McSweeney, T., Cogan, T., Eds.; Academic Press: Cambridge, MA, USA, 2004; ISBN 978-1-4613-6138-1.

5. Fox, P.; Uniacke-Lowe, T.; McSweeney, P.; O'Mahony, J. (Eds.) Heat-Induced Changes in Milk. In Dairy Chemistry and Biochemistry; Springer International Publishing: Basel, Switzerland, 2015; pp. 345-375. ISBN 978-3-319-14891-5.

6. Pirisi, A.; Pinna, G.; Papoff, C.M. Effect of milk thermisation on Fiore Sardo PDO cheese: 1. Physicochemical characteristics. Sci. Tecn. Latt. Cas. 1999, 50, 353-366.

7. EUR-Lex-31996R1236-EN-EUR-Lex. Available online: https://eur-lex.europa.eu/legal-content/IT/TXT/?uri=CELEX\% 3A31996R1236 (accessed on 26 February 2021). 
8. Anedda, R. Magnetic Resonance Analysis of Dairy Processing Suitable Tools for the Dairy Industry. In Magnetic Resonance in Food Science: Defining Food by Magnetic Resonance; The Royal Society of Chemistry: London, UK, 2015; pp. 49-64. ISBN 978-1-78262-031-0.

9. Anedda, R.; Pala, M.; Curti, E. Cheeses That Made History in Italian Dairy Tradition. In Cheeses around the World: Types, Production, Properties and Cultural and Nutritional Relevance; Ferrão, A.C., Guiné, R.P.F., Correia, P.R., Eds.; Nova Science Publishers: New York City, NY, USA, 2019; pp. 203-228. ISBN 978-1-53615-419-1.

10. Mendia, C.; Ibañez, F.C.; Torre, P.; Barcina, Y. Effect of pasteurization on the sensory characteristics of a ewe's-milk cheese. J. Sens. Stud. 1999, 14, 415-424. [CrossRef]

11. Scintu, M.F.; Del Caro, A.; Urgeghe, P.P.; Piga, C.; Di Salvo, R. Sensory profile development for an Italian PDO ewe's milk cheese at two different ripening times. J. Sens. Stud. 2010, 25, 577-590. [CrossRef]

12. Siniscalchi, V. Environment, regulation and the moral economy of food in the Slow Food movement. J. Polit. Ecol. 2013, 20, 295-305. [CrossRef]

13. Pittalis, P.; Cappellacci, U.; Contu, M.I.; Fasolino, G.; Peru, A.; Tedde, M.; Tocco, E.; Tunis, S.; Zedda, A. XV LegislatureRegional Question N.1380. Available online: http:/ / www3.consregsardegna.it/XVlegislatura/interrogazioni/1380 (accessed on 26 February 2021).

14. Ledda A XV Legislature-Regional Question N.1706/A. Available online: http:/ /www3.consregsardegna.it/XVlegislatura/ interrogazioni/1706 (accessed on 26 February 2021).

15. Siniscalchi, V. Food, Slow Food and Middle Class Activism. In Food Activism: Agency, Democracy and Economy; Bloomsbury Academic: London, UK, 2014; pp. 9-24.

16. Anedda, R.; Pardu, A.; Korb, J.P.; Curti, E. Effect of the manufacturing process on Fiore Sardo PDO cheese microstructure by multi-frequency NMR relaxometry. Food Res. Int. 2021, 140, 110079. [CrossRef]

17. Caboni, P.; Maxia, D.; Scano, P.; Addis, M.; Dedola, A.; Pes, M.; Murgia, A.; Casula, M.; Profumo, A.; Pirisi, A. A gas chromatography-mass spectrometry untargeted metabolomics approach to discriminate Fiore Sardo cheese produced from raw or thermized ovine milk. J. Dairy Sci. 2019, 102, 5005-5018. [CrossRef]

18. Dedola, A.S.; Piras, L.; Addis, M.; Pirisi, A.; Piredda, G.; Mara, A.; Sanna, G. New analytical tools for unmasking frauds in raw milk-based dairy products: Assessment, validation and application to fiore sardo PDO cheese of a RP-HPLC method for the evaluation of the $\alpha$-l-fucosidase activity. Separations 2020, 7, 40. [CrossRef]

19. Mulas, G.; Roggio, T.; Uzzau, S.; Anedda, R. A new magnetic resonance imaging approach for discriminating Sardinian sheep milk cheese made from heat-treated or raw milk. J. Dairy Sci. 2013, 96, 7393-7403. [CrossRef] [PubMed]

20. Mazza, M.; Guglielmetti, C.; Brusadore, S.; Sciuto, S.; Esposito, G.; Caramelli, M.; Peletto, S.; Acutis, P.L.; Marengo, E.; Manfredi, M.; et al. A proteomic approach to the safeguard of a typical agri-food product: Fiore sardo PDO. Adv. Dairy Res. 2019, 7. [CrossRef]

21. Piga, C.; Urgeghe, P.P.; Piredda, G.; Scintu, M.F.; Di Salvo, R.; Sanna, G. Thermal inactivation and variability of $\gamma-$ glutamyltransferase and $\alpha$-l-fucosidase enzymatic activity in sheep milk. LWT Food Sci. Technol. 2013, 54, 152-156. [CrossRef]

22. Lambelet, P.; Berrocal, R.; Ducret, F. Low resolution NMR spectroscopy: A tool to study protein denaturation: I. Application to diamagnetic whey proteins. J. Dairy Res. 1989, 56, 211-222. [CrossRef]

23. Lambelet, P.; Berrocal, R.; Renevey, F. Low-field nuclear magnetic resonance relaxation study of thermal effects on milk proteins. J. Dairy Res. 1992, 59, 517-526. [CrossRef]

24. Curti, E.; Pardu, A.; Melis, R.; Addis, M.; Pes, M.; Pirisi, A.; Anedda, R. Molecular mobility changes after high-temperature, short-time pasteurization: An extended time-domain nuclear magnetic resonance screening of ewe milk. J. Dairy Sci. 2020, 103, 9881-9892. [CrossRef]

25. Curti, E.; Pardu, A.; Del Vigo, S.; Sanna, R.; Anedda, R. Non-invasive monitoring of curd syneresis upon renneting of raw and heat-treated cow's and goat's milk. Int. Dairy J. 2019, 90. [CrossRef]

26. Curti, E.; Pardu, A.; Del Vigo, S.; Sanna, R.; Anedda, R. A low-field Nuclear Magnetic Resonance dataset of whole milk during coagulation and syneresis. Data Br. 2019, 26. [CrossRef] [PubMed]

27. Bjarnason, T.A.; Mitchell, J.R. AnalyzeNNLS: Magnetic resonance multiexponential decay image analysis. J. Magn. Reson. 2010, 206, 200-204. [CrossRef] [PubMed]

28. AOAC International. AOAC 948.12-2002, Moisture in Cheese. Method II (Rapid Screening Method): AOAC Official Method. Available online: http:/ / www.aoacofficialmethod.org/index.php?main_page=product_info\&products_id=1145 (accessed on 26 February 2021).

29. Pang, Z.; Chong, J.; Li, S.; Xia, J. MetaboAnalystR 3.0: Toward an optimized workflow for global metabolomics. Metabolites 2020, 10, 186. [CrossRef]

30. Laurence, A. NIfTI Image Converter (nii2png) for Python and Matlab / NIfTI-Image-Converter. Available online: https:// alexlaurence.github.io/NIfTI-Image-Converter/ (accessed on 26 February 2021).

31. Shrestha, A.; Mahmood, A. Review of deep learning algorithms and architectures. IEEE Access 2019, 7, 53040-53065. [CrossRef]

32. He, K.; Zhang, X.; Ren, S.; Sun, J. Deep residual learning for image recognition. In Proceedings of the 2016 IEEE Conference on Computer Vision and Pattern Recognition (CVPR), Las Vegas, NV, USA, 27-30 June 2016; pp. 770-778. 
33. Krizhevsky, A.; Sutskever, I.; Hinton, G.E. ImageNet classification with deep convolutional neural networks. In Proceedings of the 25th International Conference on Neural Information Processing Systems, Siem Reap, Cambodia, 13-16 December 2018; Curran Associates Inc.: Red Hook, NY, USA, 2012; Volume 1, pp. 1097-1105.

34. Liu, S.; Deng, W. Very deep convolutional neural network based image classification using small training sample size. In Proceedings of the 2015 3rd IAPR Asian Conference on Pattern Recognition (ACPR), Kuala Lumpur, Malaysia, 3-6 November 2015; pp. 730-734.

35. Iandola, F.N.; Moskewicz, M.W.; Ashraf, K.; Han, S.; Dally, W.J.; Keutzer, K. SqueezeNet: AlexNet-level accuracy with 50x fewer parameters and <1MB model size. arXiv 2016, arXiv:1602.07360.

36. Huang, G.; Liu, Z.; Van Der Maaten, L.; Weinberger, K.Q. Densely connected convolutional networks. In Proceedings of the 2017 IEEE Conference on Computer Vision and Pattern Recognition (CVPR), Honolulu, HI, USA, 21-26 July 2017; pp. $2261-2269$.

37. Szegedy, C.; Vanhoucke, V.; Ioffe, S.; Shlens, J.; Wojna, Z. Rethinking the inception architecture for computer vision. In Proceedings of the 2016 IEEE Conference on Computer Vision and Pattern Recognition (CVPR), Las Vegas, NV, USA, 27-30 June 2016; pp. 2818-2826.

38. Google Google Colaboratory. Available online: https://colab.research.google.com/notebooks/intro.ipynb (accessed on 26 February 2021).

39. Hills, B.P.; Takacs, S.F.; Belton, P.S. A new interpretation of proton NMR relaxation time measurements of water in food. Food Chem. 1990, 37, 95-111. [CrossRef]

40. Mariette, F.; Tellier, C.; Brule, G.; Marchal, P. Multinuclear Nmr-Study of the Ph dependent water state in skim milk and caseinate solutions. J. Dairy Res. 1993, 60, 175-188. [CrossRef]

41. Mariette, F. NMR Relaxation of Dairy Products. In Modern Magnetic Resonance; Webb, G.A., Ed.; Springer: Dordrecht, The Netherlands; Berlin, Germany, 2006; pp. 1697-1701. ISBN 978-1-4020-3894-5.

42. Gianferri, R.; D'Aiuto, V.; Curini, R.; Delfini, M.; Brosio, E. Proton NMR transverse relaxation measurements to study water dynamic states and age-related changes in Mozzarella di Bufala Campana cheese. Food Chem. 2007, 105, 720-726. [CrossRef]

43. Gianferri, R.; Maioli, M.; Delfini, M.; Brosio, E. A low-resolution and high-resolution nuclear magnetic resonance integrated approach to investigate the physical structure and metabolic profile of Mozzarella di Bufala Campana cheese. Int. Dairy J. 2007, 17, 167-176. [CrossRef]

44. Chaland, B.; Mariette, F.; Marchal, P.; De Certaines, J. ${ }^{1} \mathrm{H}$ nuclear magnetic resonance relaxometric characterization of fat and water states in soft and hard cheese. J. Dairy Res. 2000, 64, 609-618. [CrossRef]

45. Godefroy, S.; Korb, J.-P.; Creamer, L.K.; Watkinson, P.J.; Callaghan, P.T. Probing protein hydration and aging of food materials by the magnetic field dependence of proton spin-lattice relaxation times. J. Colloid Interface Sci. 2003, 267, 337-342. [CrossRef]

46. Venu, K.; Denisov, V.P.; Halle, B. Water ${ }^{1} \mathrm{H}$ magnetic relaxation dispersion in protein solutions. A quantitative assessment of internal hydration, proton exchange, and cross-relaxation. J. Am. Chem. Soc. 1997, 119, 3122-3134. [CrossRef]

47. Conte, P.; Cinquanta, L.; Lo Meo, P.; Mazza, F.; Micalizzi, A.; Corona, O. Fast field cycling NMR relaxometry as a tool to monitor Parmigiano Reggiano cheese ripening. Food Res. Int. 2021, 139, 109845. [CrossRef]

48. Boiani, M.; Fenelon, M.; FitzGerald, R.J.; Kelly, P.M. Use of 31P NMR and FTIR to investigate key milk mineral equilibria and their interactions with micellar casein during heat treatment. Int. Dairy J. 2018, 81, 12-18. [CrossRef]

49. Wahlgren, N.M.; Dejmek, P.; Drakenberg, T. A 43Ca and 31P NMR study of the calcium and phosphate equilibria in heated milk solutions. J. Dairy Res. 1990, 57, 355-364. [CrossRef]

50. Pisanu, S.; Pagnozzi, D.; Pes, M.; Pirisi, A.; Roggio, T.; Uzzau, S.; Addis, M.F. Differences in the peptide profile of raw and pasteurised ovine milk cheese and implications for its bioactive potential. Int. Dairy J. 2015, 42, 26-33. [CrossRef]

51. Grappin, R.; Beuvier, E. Possible implications of milk pasteurization on the manufacture and sensory quality of ripened cheese Int. Dairy J. 1997, 7, 751-761. [CrossRef]

52. Singh, H.; Waungana, A. Influence of heat treatment of milk on cheesemaking properties. Int. Dairy J. 2001, 11, 543-551. [CrossRef]

53. Slade, L.; Levine, H. Beyond water activity: Recent advances based on an alternative approach to the assessment of food quality and safety. Crit. Rev. Food Sci. Nutr. 1991, 30, 115-360. [CrossRef]

54. Brosnan, T.; Sun, D.-W. Inspection and grading of agricultural and food products by computer vision systems-A review. Comput. Electron. Agric. 2002, 36, 193-213. [CrossRef]

55. Narendra, V.G.; Hareesha, K.S. Quality inspection and grading of agricultural and food products by computer vision-A review. Int. J. Comput. Appl. 2010, 2. [CrossRef]

56. Wang, H.-H.; Sun, D.-W. Melting characteristics of cheese: Analysis of effect of cheese dimensions using computer vision techniques. J. Food Eng. 2002, 52, 279-284. [CrossRef]

57. Caccamo, M.; Melilli, C.; Barbano, D.M.; Portelli, G.; Marino, G.; Licitra, G. Measurement of gas holes and mechanical openness in cheese by image analysis. J. Dairy Sci. 2004, 87, 739-748. [CrossRef]

58. Ni, H.; Guansekaran, S. Image processing algorithm for cheese shred evaluation. J. Food Eng. 2004, 61, 37-45. [CrossRef]

59. Zhou, L.; Zhang, C.; Liu, F.; Qiu, Z.; He, Y. Application of deep learning in food: A review. Compr. Rev. Food Sci. Food Saf. 2019, 18, 1793-1811. [CrossRef]

60. Lundervold, A.S.; Lundervold, A. An overview of deep learning in medical imaging focusing on MRI. Z. Med. Phys. 2019, 29, 102-127. [CrossRef]

61. Weiss, K.; Khoshgoftaar, T.M.; Wang, D. A survey of transfer learning. J. Big Data 2016, 3, 9. [CrossRef] 